\title{
Periodontal CD14 mRNA expression is downregulated in patients with chronic periodontitis and type 2 diabetes
}

\author{
Dustin C. Hedgpeth ${ }^{1}$, Xiaoming Zhang ${ }^{3}$, Junfei Jin ${ }^{3,5}$, Renata S. Leite ${ }^{1,2}$, Joe W. Krayer ${ }^{1}$ and Yan Huang ${ }^{3,4^{*}}$
}

\begin{abstract}
Background: Patients with type 2 diabetes mellitus (T2DM) have increased severity of periodontitis. Toll-like receptor (TLR)4, its co-receptors CD14 and MD-2, and adaptor MyD88 play pivotal roles in lipopolysaccharide (LPS)-triggered tissue inflammation and periodontitis. This study investigated the effects of T2DM and periodontitis on TLR4, CD14, MD-2 and MyD88 mRNA expression in surgically removed periodontal tissues.

Methods: Periodontal tissue specimens were collected from 14 patients without periodontitis and T2DM (Group 1), 15 patients with periodontitis alone (Group 2), and 7 patients with both periodontitis and T2DM (Group 3). The mRNA of TLR4, CD14, MD-2 and MyD88 was quantified using real-time PCR and compared between the groups.

Results: Statistical analysis showed that periodontal expression of CD14 mRNA was significantly reduced across Groups 1,2 and $3(p=0.02)$ whereas the mRNA expression of TLR4, MD-2 and MyD88 was not significantly different among the groups. Furthermore, when patients in Groups 1 and 2 were combined $(n=22)$, the CD14 mRNA expression was significantly lower than that in patients of Group $1(p=0.04)$.

Conclusions: CD14 mRNA expression was downregulated across patients with neither periodontitis nor T2DM, patients with periodontitis alone and patients with both diseases, suggesting that CD14 mRNA expression is associated with a favorable host response or subjected to a negative feedback regulation.
\end{abstract}

Keywords: Periodontitis, CD14, TLR4, Diabetes, Gene expression

\section{Background}

Gram-negative bacteria are the major pathogens involved in periodontitis, which is characterized by inflammatory tissue destruction of tooth-supporting structures [1]. Studies have established that host immune-inflammatory response to Gram-negative bacteria-derived lipopolysaccharide (LPS) plays a pivotal role in the initiation and progression of periodontitis [2]. As a major breakthrough in periodontal research, Beutler and his coworkers discovered in 1998 that toll-like receptor (TLR)4 is LPS receptor and mediates LPS-triggered signaling transduction [3]. LPS-triggered TLR4 activation leads to an increased secretion of

\footnotetext{
* Correspondence: huangyan@musc.edu

${ }^{3}$ Division of Endocrinology, Diabetes and Medical Genetics, Department of Medicine, College of Medicine, Medical University of South Carolina, 114 Doughty Street, Charleston, SC 29425, USA

${ }^{4}$ Ralph H. Johnson VA Medical Center, 114 Doughty Street, Charleston, SC 29401, USA

Full list of author information is available at the end of the article
}

proinflammatory cytokines, mediators and matrix metalloproteinases (MMPs) from a variety of cells including monocytes, macrophages, neutrophils, lymphocytes, and gingival fibroblasts that contribute to periodontal inflammation and tissue destruction [4]. In addition to TLR4, studies have well documented that TLR4 co-receptors CD14 and MD-2 as well as TLR4 adaptor proteins such as myeloid differentiation primary response gene 88 (MyD88) are also vitally involved in LPS-triggered inflammatory signaling [5-8].

It has been well established that periodontitis is more prevalent and severe in patients with poorly controlled type 2 diabetes mellitus (T2DM) than nondiabetic individuals [9-11]. Findings from mechanistic studies indicate that poorly controlled T2DM leads to a hyperinflammatory host response to periodontal microbiota and also impairs resolution of inflammation and repair, leading to accelerated periodontal destruction [10]. In line with these notions, increased 
periodontal expression of interleukin (IL)-6 and MMP-8 across patients with neither periodontitis nor T2DM, patients with periodontitis alone and patients with both diseases was reported by our group [12-14]. Furthermore, we have also demonstrated through our in vitro studies that high glucose enhances LPS-triggered expression of proinflammatory genes in macrophages and gingival fibroblasts [15-19], indicating that T2DM-associated factors such as hyperglycemia enhance periodontal inflammation and tissue destruction and thus exacerbate periodontitis.

In the studies to understand how T2DM increases host responsiveness to LPS, it has been shown that T2DM increases the expression of TLR4 in host cells such as monocytes [20, 21]. Given that TLR4 is the receptor for LPS, it is plausible that upregulation of TLR4 expression on cell surface renders more binding sites for LPS and thus increases cell response to LPS challenge. Therefore, it is important to determine if T2DM increases host responsiveness to LPS by enhancing the expression of TLR4 and TLR4-associated proteins in periodontal tissue. However, the effect of T2DM on periodontal expression of TLR4 and TLR4-associated proteins in patients with periodontitis has not been well established.

In this study, we hypothesized that the expression of TLR4 or TLR4-associated molecules such as CD14, MD-2 and MyD88 are regulated by periodontitis and T2DM. To test our hypothesis, we collected periodontal tissues from patients with or without periodontitis and T2DM at the time of necessary surgeries and determined the mRNA expression of TLR4, CD14, MD-2 and MyD88 using quantitative real-time polymerase chain reaction (PCR).

\section{Methods \\ Patients}

Thirty-six patients were selected from a population referred to the Post-doctoral Periodontics Program in the College of Dental Medicine at the Medical University of South Carolina, Charleston, South Carolina. Patients recruited included 14 individuals who did not have periodontitis and T2DM (group 1), 15 patients with periodontitis only (group 2), and 7 patients with both diseases (group 3). The patients in group 1 who required non-periodontal disease-related surgeries, such as crown lengthening and extractions served as controls. All the tissues collected were periodontal tissues taken as collars from the gingival margin to include both epithelium and connective tissue.

The patients from group 2 and group 3 met the following diagnostic criteria for periodontitis [12-14]: A periodontal probing depth (PD) of $\geq 5 \mathrm{~mm}$ at two or more teeth, or clinical attachment level (AL) of $\geq 5 \mathrm{~mm}$ at two or more teeth. The exclusion criteria were as follows: Patients who were pregnant or unsure about pregnancy status, serum creatinine $\geq 1.6 \mathrm{mg} / \mathrm{dL}$, abnormal hepatic function, hemoglobinopathy (sickle cell trait/ hemolytic anemia) interfering with hemoglobin A1c (HbA1c) monitoring, aggressive periodontitis, platelet and coagulation disorders, and/or unwillingness to sign the informed consent form or enter the study. An oral examination including periodontal $\mathrm{PD}$ and clinical $\mathrm{AL}$ was performed. Six sites (mesio-buccal, buccal, distobuccal, disto-lingual, lingual and mesio-lingual) were examined for each tooth, excluding third molars. Probing depth was defined as the distance from the free gingival margin to the bottom of the sulcus while gingival recession was defined as the distance from the cementoenamel junction to the free gingival margin. Clinical AL was calculated as the sum of PD and gingival recession. The patients in groups 2 and 3 had periodontal surgery for the treatment of periodontitis and their periodontal tissue, including epithelium and connective tissue, were removed from sites based on the greatest PD and/or AL. The PD and AL reported in this study were related to the surgery sites. The HbA1c test was carried out on all patients to document their glycemic status. T2DM was diagnosed previously for all patients in Group 3. All patients provided informed consent for specimen collection. The study protocol and consent forms were approved by the Medical University of South Carolina's Institutional Review Board (Approval number: Pro00010000).

\section{Isolation of RNA and RNA Reverse Transcription (RT)}

Total RNA was isolated from periodontal tissue specimens using the RNeasy minikit (Qiagen, Santa Clarita, CA). The first-strand complementary DNA (cDNA) was synthesized with the iScript ${ }^{\mathrm{Tm}}$ cDNA synthesis kit (Bio-Rad, Hercules, CA) by following the instruction provided by the manufacturer. The reaction was cycled for $5 \mathrm{~min}$ at $25^{\circ} \mathrm{C}, 30 \mathrm{~min}$ at $42{ }^{\circ} \mathrm{C}$ and $5 \mathrm{~min}$ at $85{ }^{\circ} \mathrm{C}$ using a PTC-200 DNA Engine (MJ Research, Waltham, MA).

\section{Quantitative real-time PCR}

The RT reaction mixture from the above experiments was then subjected to real-time PCR amplification. The Beacon Designer Software (PREMIER Biosoft International, Palo Alto, CA) was used for designing primers (Table 1). Primers were synthesized by Integrated DNA Technologies, Inc. (Coralville, IA). PCR was carried out in duplicates using a $25 \mu \mathrm{l}$ reaction mixture that contained $1.5 \mu \mathrm{l}$ R reaction mixture, $0.2 \mu \mathrm{M}$ of both primers and $12.5 \mu \mathrm{l}$ of $\mathrm{iQ}^{\mathrm{TM}}$ SYBR Green Supermix (BioRad). The PCR reaction was performed with the iCycler ${ }^{\text {ra }}$ Real-Time Detection System (Bio-Rad). Forty cycles consisting of denaturation $\left(95^{\circ} \mathrm{C}\right.$ for $10 \mathrm{~s}$ ) and annealing/extension $\left(56{ }^{\circ} \mathrm{C}\right.$ for $\left.45 \mathrm{~s}\right)$ were run. A melt-curve 
Table 1 The primer sequences for real-time PCR

\begin{tabular}{lll}
\hline Genes & 5' Primer sequence & 3' Primer sequence \\
\hline CD14 & CCGCTGCCTCTGGAAG & GGCGAGTGTGCTGGG \\
TLR4 & GTCCTCAGTGTGCTTGTAG & ATCCTGGCTTGAGTAGATAAC \\
MD-2 & CACCATGAATCTTCCAAAGC & CTTGAAGGAGAATGATATTGTTG \\
MyD88 & CGGATGGTGGTGGTTGTCTC & CGCTTCTGATGGGCACCT \\
GAPDH & CTGAGTACGTCGTGGAGTC & AAATGAGCCCCAGCCTTC \\
\hline
\end{tabular}

experiment was subsequently performed $\left(55{ }^{\circ} \mathrm{C}\right.$ for $1 \mathrm{~min}$ and then temperature is increased by $0.5{ }^{\circ} \mathrm{C}$ every $10 \mathrm{~s})$ to detect the primer dimers. Data were analyzed with the SmartCycler II software. The average threshold cycle $(C t)$ of fluorescent units was used for analysis. Quantification was calculated using the $C t$ of the target signal relative to that of glyceraldehyde-3-phosphate dehydrogenase (GAPDH) signal in the same RNA sample.

\section{Statistical analysis}

The age, gender and race of the study participants are presented as counts and the continuous variables are presented as medians. The GraphPad Instat 3 software (GraphPad Software, Inc., San Diego, CA) was used for statistical analysis. Nonparametric analyses testing for any differences in continuous variables among groups greater than two were performed using the KruskalWallis procedure. Nonparametric analysis testing for any difference in variables between two groups was performed using the Mann-Whitney procedure. A value of $p<0.05$ was considered significant. The correlation analysis on the relationship between CD14 mRNA expression and PD, AL or HbA1c was evaluated by Pearson's method. Our previous studies have indicated that the sample size of 7 or greater provided sufficient power to detect the difference of periodontal mRNA expression of IL-6 and MMP-8 across control individuals who did not have periodontitis and T2DM, patients with periodontitis alone and patients with both periodontitis and diabetes [13, 14].

\section{Results}

\section{Study population}

The clinical data for patient age, gender, race, smoking status, $\mathrm{HbA1c}$, periodontal $\mathrm{PD}$, and $\mathrm{AL}$ were presented in Table 2.

Age - The ages of subjects in groups 1, 2, and 3 ranged from 42 to 79,40 to 79 , and 52 to 71 with a mean \pm standard deviation of $58 \pm 11,56 \pm 11$, and $63 \pm 6$, respectively. No significant difference between groups was found.

Gender - The ratios of male/female gender in groups 1 , 2 , and 3 were $3.7(11 / 3), 2(10 / 5)$, and 7 (7/0), respectively. No significant difference was found between the groups.

Race - The ratios of Caucasians vs. African Americans in groups 1, 2, and 3 were 6.0 (12/2), 2.8 (11/4), and and $0.17(1 / 6)$, respectively. Statistical analysis indicated that African Americans in group 3 were significantly more than those in group 1 or group 2, which is consistent with the previous reports that African Americans have a high risk of developing T2DM and periodontitis [22, 23].

Smoking status - The smoker/nonsmoker ratios in groups 1, 2, and 3 were 0.4 (4/10), 1.5 (9/6), and 2.5 (5/2), respectively. Statistical analysis indicated that smokers in group 2 and group 3 were significantly more than those in group 1, which is consistent with the previous reports that smoking is associated with a high risk for periodontitis [24].

Periodontitis - The PD in groups 1,2 and 3 was $2.45 \pm$ $0.86,4.20 \pm 2.00$ and $4.80 \pm 2.32 \mathrm{~mm}$, respectively. The $\mathrm{AL}$ in groups 1,2 and 3 was $2.48 \pm 0.89,5.03 \pm 2.48$ and $5.24 \pm 2.39 \mathrm{~mm}$, respectively. A significant difference of PD and AL was found between group 1 and group 2 or group 3 , but no significant difference of $\mathrm{PD}$ and AL was found between group 2 and group 3.

Diabetes - All patients in group 3 reported having T2DM. The mean HbA1c in Groups 3 ranged from $7.0 \%$ to $10.7 \%$ with a mean \pm standard deviation of $8.19 \pm$ $1.24 \%$ that is significantly higher than $5.81 \pm 0.55 \%$ and

Table 2 Patients and periodontal disease in three groups

\begin{tabular}{llll}
\hline & $\begin{array}{l}\text { Group 1: Patients without } \\
\text { diabetes and periodontitis }\end{array}$ & $\begin{array}{l}\text { Group 2: Patients with } \\
\text { periodontitis alone }\end{array}$ & $\begin{array}{l}\text { Group 3: Patients with both } \\
\text { periodontitis and diabetes }\end{array}$ \\
\hline Patient number & 14 & 15 & 7 \\
Age & $58 \pm 11$ & $56 \pm 11$ & $63 \pm 6$ \\
Gender (male/female) & $11 / 3$ & $10 / 5$ & $7 / 0$ \\
Race and ethnicity & & & $0.17(1 / 6) *$ \\
Caucasians/African Americans (nonhispanic) & $6.0(12 / 2)$ & $2.8(11 / 4)$ & $2.5(5 / 2)$ \\
Smoking status (smokers/nonsmokers) & $0.4(4 / 10)+$ & $1.5(9 / 6)$ & $8.19 \pm 1.24 *$ \\
HbA1c (\%) & $5.81 \pm 0.55$ & $5.60 \pm 0.56$ & $4.80 \pm 2.32$ \\
PD (mm) & $2.45 \pm 0.86+$ & $4.20 \pm 2.00$ & $5.24 \pm 2.39$ \\
AL (mm) & $2.48 \pm 0.89+$ & $5.03 \pm 2.48$ & \\
\hline
\end{tabular}

The data are mean \pm SD. ${ }^{*} p<0.05$ vs group 1 or group $2 ;+p<0.05$ vs group 2 or group 3 . PD Probing depth, AL Attachment level 
$5.60 \pm 0.56 \%$, respectively, in Group 1 and Group 2. Four of the seven patients were prescribed metformin alone or in combination with Glucotrol (Glipizide, Pfizer) or NPH insulin (Humulin, Eli Lily and Company). One patient was prescribed insulin Glargine (Lantus, Sanofi-Aventis), one patient was prescribed insulin Aspart (NovoLog, Novo Nordisk), and one patient did not report taking any medication for diabetes.

\section{Periodontal expression of CD14, TLR4, MD-2 and MyD88 in three groups}

The expression of CD14, TLR4, MD-2, and MyD88 in surgically removed periodontal tissues was successfully quantified using real-time PCR. As shown in Table 3, CD14 expression was highest among four genes in patients without periodontitis and T2DM (Group 1). Our statistical analysis using nonparametric Kruskal-Wallis test showed that the periodontal expression of TLR4, MD-2 and MyD88 had no significant difference among the 3 groups. Interestingly, CD14 expression was found to be significantly downregulated across Groups 1, 2 and 3 $(p=0.020)$. We also compared the CD14 expression between two groups. Results showed that although CD14 expression in Group 2 (patients with periodontitis alone) is lower than that in Group 1 (patients without both periodontitis and T2DM), the difference is not statistically significant. However, when the patients in Group 2 were combined with Group 3 (patients with both periodontitis and T2DM), the CD14 expression was significantly lower than that in Group $1(p=0.04)$ (Table 4$)$. Furthermore, we found that CD14 expression in Group 3 is significantly lower than that in Group $1(p=0.003)$, indicating that periodontal CD14 expression in patients with both periodontitis and T2DM is significantly lower than that in patients without periodontitis and T2DM.
The relationship between CD14 mRNA expression and PD, AL or HbA1c

The relationship between CD14 mRNA expression and $\mathrm{PD}, \mathrm{AL}$ or HbA1c was statistically analyzed and no significant correlations were found between CD14 mRNA expression and these clinical parameters (Table 5).

\section{Discussion}

Our current study demonstrated that CD14 mRNA level was significantly reduced across patients with neither periodontitis nor T2DM, patients with periodontitis alone, and patients with both periodontitis and T2DM, suggesting that periodontitis and T2DM negatively regulates CD14 gene expression in periodontal tissue. Our findings are consistent with those by Jin et al., who reported that the CD14 protein level in gingival biopsy tissues from patients with periodontitis was significantly lower than that in subjects without periodontitis [25]. They also reported that the level of secreted CD14 in gingival crevicular fluid (GCF) was lower in patients with more deep pockets than that in patients with less deep pockets [26]. Since their studies were focused on CD14 protein level in periodontal tissue, it remains unclear if the decreased CD14 protein level is the result of downregulation of CD14 mRNA expression that may suggest the involvement of transcriptional regulation of CD14 expression. Our current study has provided the new insight into the mechanisms involved in the regulation of CD14 expression.

In the current study, we employed real-time PCR technique to quantify the mRNA expression level of TLR4, CD14, MD-2 and MyD88 in periodontal tissue. It is well known that regulation of cytokine expression at the mRNA level via nuclear factor-kappa B (NFkB)-mediated transcriptional activation plays a crucial role in periodontitis [27]. Therefore, studies investigating gene expression at the mRNA levels are important for

Table 3 Periodontal expression of CD14, TLR4, MD-2 and MyD88 in three groups

\begin{tabular}{|c|c|c|c|c|c|}
\hline & \multirow{2}{*}{$\begin{array}{l}\text { Group } 1(n=14) \\
\text { Without both periodontitis } \\
\text { and diabetes }\end{array}$} & \multirow{2}{*}{$\begin{array}{l}\text { Group } 2(n=15) \\
\text { With periodontitis, } \\
\text { without diabetes }\end{array}$} & \multirow{2}{*}{$\begin{array}{l}\text { Group } 3(n=7) \\
\text { With both periodontitis } \\
\text { and diabetes }\end{array}$} & \multicolumn{2}{|c|}{$\begin{array}{l}\text { Nonparametric analyses (Kruskal-Wallis test) } \\
\text { for any differences in groups }\end{array}$} \\
\hline & & & & Test statistic & $P$-value \\
\hline \multirow[t]{2}{*}{ CD14 } & 1.92 & 1.39 & 0.68 & 7.81 & 0.02 \\
\hline & $(0.78,11.88)$ & $(0.30,17.80)$ & $(0.17,1.66)$ & & \\
\hline \multirow[t]{2}{*}{ TLR4 } & 0.74 & 0.58 & 0.74 & 0.97 & 0.62 \\
\hline & $(0.28,5.25)$ & $(0.15,18.31)$ & $(0.14,1.25)$ & & \\
\hline \multirow[t]{2}{*}{ MD-2 } & 0.46 & 0.35 & 0.50 & 1.49 & 0.48 \\
\hline & $(0.21,2.96)$ & $(0.04,5.76)$ & $(0.19,1.66)$ & & \\
\hline \multirow[t]{2}{*}{ MyD88 } & 0.81 & 0.61 & 0.71 & 3.32 & 0.19 \\
\hline & $(0.50,1.21)$ & $(0.22,2.19)$ & $(0.45,1.01)$ & & \\
\hline
\end{tabular}


Table 4 The difference of CD14 expression between patients in Group 1 and combined patients in Group 2 and Group 3

\begin{tabular}{llll} 
& $\begin{array}{l}\text { Group 1 (patients } \\
\text { without periodontitis) }\end{array}$ & $\begin{array}{l}\text { Combination of Group 2 } \\
\text { (patients with periodontitis alone) and Group 3 } \\
\text { (patients with both periodontitis and diabetes) }\end{array}$ & $\begin{array}{c}\text { Two-tailed } \\
P \text { value }\end{array}$ \\
\hline Patient number & 14 & 22 & 0.04 \\
Median (minimum, Maximum) & $1.92(0.78,11.88)$ & $1.22(0.17,17.80)$ \\
\hline
\end{tabular}

Data presented are medians (minimum, maximum)

understanding the molecular mechanisms involved in the pathogenesis of periodontitis. Furthermore, since real-time PCR is a fully quantitative method and well controlled by normalization to the housekeeping gene, the data are valuable for assessment of gene expression. In addition to real-time PCR quantification of gene expression at the mRNA level, immunohistochemistry and immunofluorescence are also commonly employed in the studies of gene expression at the protein level. While these methods have advantages in the characterization of tissue or cell specific gene expression at the protein level, they also have disadvantage as a semi-quantitative approach [28] that may lead to inter-study variability. For example, by using immunohistochemistry, one study showed that periodontitis decreased TLR4 [29] but another study demonstrated that periodontitis increased TLR4 level in the gingival epithelium [30].

CD14 was characterized as LPS receptor in 1990 [31], almost a decade before the discovery of TLR4. While TLR4 has a transmembrane domain for LPS-triggered signal transduction, CD14 lacks the transmembrane domain and is unable to transmit LPS signaling. CD14 is anchored with glycosylphosphatidylinositol (GPI) on the cell surface and expressed as a 55-kDa glycoprotein [32]. In addition to the membrane-bound form (mCD14), $\mathrm{CD} 14$ is also expressed as a soluble form (sCD14) by secretion of CD14 without coupling to the GPI anchor or from shedding or cleavage from mCD14 [33]. The major function of CD14 is to serve as an initial receptor for LPS and facilitate the binding of LPS to TLR4/MD-2 complex [34]. In addition, CD14 also recognizes other pathogen-associated molecular patterns such as lipoteichoic acid [35].

Previous studies have shown that CD14 has dual roles in response to Gram-negative bacteria [36]. For examples, one study showed that neutralization of CD14 prevented LPS-induced uncontrolled proinflammatory

Table 5 The relationship between CD14 mRNA expression and $\mathrm{PD}, \mathrm{AL}$ or $\mathrm{HbA} 1 \mathrm{c}$

\begin{tabular}{lllll}
\hline & & PD & AL & HbA1c \\
\hline CD14 mRNA expression & $n$ & 36 & 36 & 36 \\
& $r$ & -0.1271 & -0.1862 & -0.1967 \\
& $p$ & 0.4602 & 0.2770 & 0.2500 \\
\hline
\end{tabular}

PD Probing depth, AL Attachment level response and subsequent host death [37], revealing a proinflammatory effect of CD14. Another study, however, reported that when CD14 was blocked, animals infected with Shigella, a diarrheal pathogen, exhibited a 50-fold increase in bacterial invasion and more severe tissue injury compared with animals without CD14 blocking [38], indicating an anti-inflammatory effect of CD14. These studies suggest that while downregulation of periodontal CD14 expression reduces the stimulatory effect of LPS on proinflammatory signaling, it may also impair the innate immunity against LPS-independent pathogens and thus increases tissue inflammation.

Previous studies have also shown the dual roles of CD14 in T2DM. On one hand, it was reported that CD14 expression was significantly associated with T2DM and correlated with serum concentrations of Creactive protein [39]; On the other hand, it was reported that injection of recombinant human soluble CD14 to diabetic mice increased insulin action [40] and the mice with CD14-deficiency displayed significant glucose intolerance [41], suggesting a beneficial role of CD14 in insulin signaling and glucose homeostatsis.

The finding that CD14 was downregulated in patients with periodontitis may also reveal a negative feedback mechanism by which periodontal tissue of patients with periodontitis prevent further damage from repeated attacks by bacteria-derived LPS. Interestingly, Nemoto et al. reported that CD14 expression on human gingival fibroblasts (HGFs) was markedly reduced by phorbol 12-myristate 13-acetate (PMA)-activated polymorphonuclear leukocytes (PMNs) in a coculture system of HGF and PMNs [42]. Their further investigation showed that as a result of CD14 reduction, LPSinduced production of inflammatory cytokines such as IL- 8 by HGFs was suppressed. These findings suggested that while activated PMNs play a crucial role in tissue inflammation, HGFs have a potential negative feedback mechanism to control inflammation by downregulation of CD14 expression.

In addition to CD14, our current study also examined the periodontal expression of TLR4, MD-2 and MyD88. Results showed that the periodontal mRNA expressions of TLR4, MD-2 and MyD88 had no significant difference across the 3 groups. While our current study is the first one focusing on TLR4 mRNA expression, Promsudthi et al. and Rojo-Botello et al. have reported the effect of 
T2DM and chronic periodontitis on TLR4 protein expression $[29,30]$. Promsudthi et al. showed that patients with periodontitis had reduced TLR4 protein in gingival epithelium, but patients with both periodontitis and diabetes had statistically significant higher percentages of TLR4-positive cells as compared with periodontally healthy subjects [29]. Rojo-Botello et al. demonstrated that patients with periodontitis and diabetes had a higher TLR4 protein in gingival epithelium than patients with periodontitis alone. Obviously, these studies focused on the periodontal TLR4 protein expression, but our study aimed at the TLR4 mRNA expression.

It has been well documented that CD14 expression is upregulated by LPS and inflammatory cytokines in vitro [43-45]. However, the mechanisms involved in the downregulation of CD14 expression have not been well established. In addition to the inhibition of CD14 expression by PMNs as described above, Imai et al. have reported that transforming growth factor beta (TGF $\beta) 1$ is capable of inhibiting LPS-stimulated CD14 expression in macrophages by reducing transcription factor activating protein (AP)-1 [46]. Interestingly, our recent study has shown that periodontal TGF $\beta 1$ expression is increased in patients with periodontitis [47]. Therefore, it is likely that TGF $\beta 1$ plays a role in the downregulation of periodontal CD14 expression in patients with periodontitis. Nevertheless, it remains unclear how CD14 expression is further downregulated by T2DM and more studies are necessary to elucidate the mechanisms by which periodontal CD14 expression is downregulated by periodontitis and T2DM.

\section{Conclusions}

CD14 expression was downregulated across patients with neither periodontitis nor T2DM, patients with periodontitis alone, and patients with both periodontitis and T2DM. This finding indicates that CD14 expression is associated with a favorable host response or subjected to a negative feedback regulation.

\section{Abbreviations}

TLR: Toll like receptor; LPS: Lipopolysaccharide; MyD88: Myeloid

differentiation primary response gene $88, \mathrm{MD}-2$, Myeloid differentiation factor 2; PD: Probing depth; AL: Attachment level.

\section{Competing interests}

The authors declare that they have no competing interests.

\section{Authors' contributions}

DCH: Dr. Hedgpeth is a periodontist who recruited patients, collected periodontal tissues after surgeries and provided clinical data. XZ: Xiaoming is a research specialist who carried out RNA isolation and gene expression analysis using real-time PCR. JJ: Dr. Jin is a staff scientist who performed gene expression analysis using real-time PCR and data analysis. RSL: Dr. Leite is a periodontist who recruited patients, collected periodontal tissues after surgeries, provided clinical data, and contributed to manuscript preparation. JWK: Dr. Krayer is a periodontist who contributed to manuscript preparation. YH: Dr. Huang is a senior investigator overseeing the project including obtaining ethical approval, experimental design, data analysis and manuscript preparation. All authors read and approved the final manuscript.

\section{Acknowledgements}

This work was supported by National Institute of Dental and Craniofacial Research (NIDCR)/National Institutes of Health (NIH) grant DE016353 and Department of Veterans Affairs, Veterans Health Administration, Office of Research and Development, Biomedical Laboratory Research and Development grant 5101BX000854 (to Y.H.).

\section{Author details}

'Department of Stomatology, James B. Edwards College of Dental Medicine, Medical University of South Carolina, Charleston, SC 29425, USA. ${ }^{2}$ Center for Oral Health Research, James B. Edwards College of Dental Medicine, Medical University of South Carolina, Charleston, SC 29425, USA. ${ }^{3}$ Division of Endocrinology, Diabetes and Medical Genetics, Department of Medicine, College of Medicine, Medical University of South Carolina, 114 Doughty Street, Charleston, SC 29425, USA. ${ }^{4}$ Ralph H. Johnson VA Medical Center, 114 Doughty Street, Charleston, SC 29401, USA. ${ }^{5}$ Laboratory of Hepatobiliary and Pancreatic Surgery, Affiliated Hospital of Guilin Medical University, Guilin 541001, Guangxi, People's Republic of China.

Received: 17 May 2015 Accepted: 15 October 2015

Published online: 18 November 2015

\section{References}

1. Page RC. The pathobiology of periodontal diseases may affect systemic diseases: inversion of a paradigm. Ann Periodontol. 1998;3(1):108-20

2. Page RC, Offenbacher S, Schroeder HE, Seymour GJ, Kornman KS. Advances in the pathogenesis of periodontitis: summary of developments, clinical implications and future directions. Periodontol 2000. 1997;14:216-48.

3. Poltorak A, He X, Smirnova I, Liu MY, Van Huffel C, Du X, et al. Defective LPS signaling in C3H/HeJ and C57BL/10ScCr mice: mutations in Trr4 gene. Science. 1998;282(5396):2085-8.

4. Gu Y, Lee HM, Sorsa T, Salminen A, Ryan ME, Slepian MJ, et al. Nonantibacterial tetracyclines modulate mediators of periodontitis and atherosclerotic cardiovascular disease: a mechanistic link between local and systemic inflammation. Pharmacol Res. 2011;64(6):573-9.

5. Peri F, Piazza M. Therapeutic targeting of innate immunity with Toll-like receptor 4 (TLR4) antagonists. Biotechnol Adv. 2012;30(1):251-60.

6. Stoll LL, Denning GM, Weintraub NL. Endotoxin, TLR4 signaling and vascular inflammation: potential therapeutic targets in cardiovascular disease. Curr Pharm Des. 2006;12(32):4229-45.

7. Christiansen D, Brekke OL, Stenvik J, Lambris JD, Espevik T, Mollnes TE. Differential effect of inhibiting MD-2 and CD14 on LPS- versus whole E. coli bacteria-induced cytokine responses in human blood. Adv Exp Med Biol. 2012;946:237-51.

8. O'Neill LA, Dunne A, Edjeback M, Gray P, Jefferies C, Wietek C. Mal and MyD88: adapter proteins involved in signal transduction by Toll-like receptors. J Endotoxin Res. 2003;9(1):55-9.

9. Preshaw PM, Alba AL, Herrera D, Jepsen S, Konstantinidis A, Makrilakis $K$, et al. Periodontitis and diabetes: a two-way relationship. Diabetologia. 2012;55(1):21-31.

10. Lalla E, Papapanou PN. Diabetes mellitus and periodontitis: a tale of two common interrelated diseases. Nat Rev Endocrinol. 2011;7(12):738-48.

11. Lalla E, Lamster IB, Drury S, Fu C, Schmidt AM. Hyperglycemia, glycoxidation and receptor for advanced glycation endproducts: potential mechanisms underlying diabetic complications, including diabetes-associated periodontitis. Periodontol 2000. 2000;23:50-62.

12. Ross JH, Hardy DC, Schuyler CA, Slate EH, Mize TW, Huang Y. Expression of periodontal interleukin-6 protein is increased across patients with neither periodontal disease nor diabetes, patients with periodontal disease alone and patients with both diseases. J Periodontal Res. 2010;45(5):688-94.

13. Cole CM, Sundararaj KP, Leite RS, Nareika A, Slate EH, Sanders JJ, et al. A trend of increase in periodontal interleukin- 6 expression across patients with neither diabetes nor periodontal disease, patients with periodontal disease alone, and patients with both diseases. J Periodontal Res. 2008;43(6):717-22.

14. Hardy DC, Ross JH, Schuyler CA, Leite RS, Slate EH, Huang Y. Matrix metalloproteinase-8 expression in periodontal tissues surgically removed 
from diabetic and non-diabetic patients with periodontal disease. J Clin Periodontol. 2012;39(3):249-55.

15. Li Y, Samuvel DJ, Sundararaj KP, Lopes-Virella MF, Huang Y. IL-6 and high glucose synergistically upregulate MMP-1 expression by U937 mononuclear phagocytes via ERK1/2 and JNK pathways and c-Jun. J Cell Biochem. 2010;110(1):248-59.

16. Maldonado A, He L, Game BA, Nareika A, Sanders JJ, London SD, et al. Pre-exposure to high glucose augments lipopolysaccharide-stimulated matrix metalloproteinase-1 expression by human U937 histiocytes. J Periodontal Res. 2004;39(6):415-23.

17. Nareika A, Im YB, Game BA, Slate EH, Sanders JJ, London SD, et al. High glucose enhances lipopolysaccharide-stimulated CD14 expression in U937 mononuclear cells by increasing nuclear factor kappaB and AP-1 activities. J Endocrinol. 2008;196(1):45-55.

18. Nareika A, Maldonado A, He L, Game BA, Slate EH, Sanders JJ, et al. High glucose-boosted inflammatory responses to lipopolysaccharide are suppressed by statin. J Periodontal Res. 2007:42(1):31-8.

19. Sundararaj KP, Samuvel DJ, Li Y, Sanders JJ, Lopes-Virella MF, Huang Y. Interleukin-6 released from fibroblasts is essential for up-regulation of matrix metalloproteinase-1 expression by U937 macrophages in coculture: crosstalking between fibroblasts and U937 macrophages exposed to high glucose. J Biol Chem. 2009;284(20):13714-24.

20. Jialal I, Huet BA, Kaur H, Chien A, Devaraj S. Increased toll-like receptor activity in patients with metabolic syndrome. Diabetes Care. 2012;35(4):900-4

21. Dasu MR, Devaraj S, Park S, Jialal I. Increased toll-like receptor (TLR) activation and TLR ligands in recently diagnosed type 2 diabetic subjects. Diabetes Care. 2010:33(4):861-8.

22. Marshall Jr MC. Diabetes in African Americans. Postgrad Med J. 2005:81(962):734-40.

23. Taylor GW. Exploring interrelationships between diabetes and periodontal disease in African Americans. Compend Contin Educ Dent. 2001;22(3 Spec No):42-8.

24. Haber J. Smoking is a major risk factor for periodontitis. Curr Opin Periodontol. 1994:12-18.

25. Jin L, Ren L, Leung WK, Darveau RP. The in vivo expression of membranebound CD14 in periodontal health and disease. J Periodontol. 2004;75(4):578-85.

26. Jin L, Darveau RP. Soluble CD14 levels in gingival crevicular fluid of subjects with untreated adult periodontitis. J Periodontol. 2001;72(5):634-40.

27. Nichols TC, Fischer TH, Deliargyris EN, Baldwin Jr AS. Role of nuclear factorkappa B (NF-kappa B) in inflammation, periodontitis, and atherogenesis. Ann Periodontol. 2001:6(1):20-9.

28. Dietel M, Johrens K, Laffert M, Hummel M, Blaker H, Muller BM, et al. Predictive molecular pathology and its role in targeted cancer therapy: a review focussing on clinical relevance. Cancer Gene Ther. 2013;20(4):211-21.

29. Promsudthi A, Poomsawat S, Limsricharoen $W$. The role of Toll-like receptor 2 and 4 in gingival tissues of chronic periodontitis subjects with type 2 diabetes. J Periodontal Res. 2014;49(3):346-54.

30. Rojo-Botello NR, Garcia-Hernandez AL, Moreno-Fierros L. Expression of toll-like receptors 2, 4 and 9 is increased in gingival tissue from patients with type 2 diabetes and chronic periodontitis. J Periodontal Res. 2012:47(1):62-73.

31. Wright SD. CD14 and innate recognition of bacteria. J Immunol. 1995;155(1):6-8.

32. Wright SD, Ramos RA, Tobias PS, Ulevitch RJ, Mathison JC. CD14, a receptor for complexes of lipopolysaccharide (LPS) and LPS binding protein. Science. 1990;249(4975):1431-3

33. Tapping RI, Tobias PS. Soluble CD14-mediated cellular responses to lipopolysaccharide. Chem Immunol. 2000;74:108-21.

34. Beutler B, Rietschel ET. Innate immune sensing and its roots: the story of endotoxin. Nat Rev Immunol. 2003;3(2):169-76.

35. Ranoa DR, Kelley SL, Tapping RI. Human lipopolysaccharide-binding protein (LBP) and CD14 independently deliver triacylated lipoproteins to Toll-like receptor 1 (TLR1) and TLR2 and enhance formation of the ternary signaling complex. J Biol Chem. 2013;288(14):9729-41.

36. Heumann D, Lauener R, Ryffel B. The dual role of LBP and CD14 in response to Gram-negative bacteria or Gram-negative compounds. J Endotoxin Res. 2003;9(6):381-4.

37. Schimke J, Mathison J, Morgiewicz J, Ulevitch RJ. Anti-CD14 mAb treatment provides therapeutic benefit after in vivo exposure to endotoxin. Proc Natl Acad Sci U S A. 1998;95(23):13875-80
38. Wenneras C, Ave P, Huerre M, Arondel J, Ulevitch RJ, Mathison JC, et al. Blockade of CD14 increases Shigella-mediated invasion and tissue destruction. J Immunol. 2000;164(6):3214-21.

39. Patino R, Ibarra J, Rodriguez A, Yague MR, Pintor E, Fernandez-Cruz A, et al. Circulating monocytes in patients with diabetes mellitus, arterial disease, and increased CD14 expression. Am J Cardiol. 2000;85(11):1288-91.

40. Fernandez-Real JM, Perez Del Pulgar S, Luche E, Moreno-Navarrete JM, Waget $A$, Serino $M$, et al. CD14 modulates inflammation-driven insulin resistance. Diabetes. 2011;60(8):2179-86.

41. Young JL, Mora A, Cerny A, Czech MP, Woda B, Kurt-Jones EA, et al. CD14 deficiency impacts glucose homeostasis in mice through altered adrenal tone. PLoS One. 2012;7(1):e29688.

42. Nemoto E, Sugawara S, Tada H, Takada H, Shimauchi H, Horiuchi H. Cleavage of CD14 on human gingival fibroblasts cocultured with activated neutrophils is mediated by human leukocyte elastase resulting in down-regulation of lipopolysaccharide-induced IL-8 production. J Immunol. 2000;165(10):5807-13.

43. Liu S, Khemlani LS, Shapiro RA, Johnson ML, Liu K, Geller DA, et al. Expression of CD14 by hepatocytes: upregulation by cytokines during endotoxemia. Infect Immun. 1998;66(11):5089-98.

44. Matsuura K, Ishida T, Setoguchi M, Higuchi Y, Akizuki S, Yamamoto S. Upregulation of mouse CD14 expression in Kupffer cells by lipopolysaccharide. J Exp Med. 1994;179(5):1671-6.

45. Parajuli B, Sonobe $Y$, Kawanokuchi J, Doi Y, Noda M, Takeuchi H, et al. GM-CSF increases LPS-induced production of proinflammatory mediators via upregulation of TLR4 and CD14 in murine microglia. J Neuroinflammation. 2012;9:268.

46. Imai K, Takeshita A, Hanazawa S. Transforming growth factor-beta inhibits lipopolysaccharide-stimulated expression of inflammatory cytokines in mouse macrophages through downregulation of activation protein 1 and CD14 receptor expression. Infect Immun. 2000;68(5):2418-23.

47. Mize TW, Sundararaj KP, Leite RS, Huang Y. Increased and correlated expression of connective tissue growth factor and transforming growth factor beta 1 in surgically removed periodontal tissues with chronic periodontitis. J Periodontal Res. 2015;50(3):315-9.

\section{Submit your next manuscript to BioMed Central and take full advantage of:}

- Convenient online submission

- Thorough peer review

- No space constraints or color figure charges

- Immediate publication on acceptance

- Inclusion in PubMed, CAS, Scopus and Google Scholar

- Research which is freely available for redistribution 